\title{
A Dimensão Relacional da Intervenção dos Serviços de Psicologia nas Escolas
}

\section{The Relational Dimension of the Intervention of Psychology Services in Schools}

\author{
Renato Gil Gomes Carvalho* \\ Secretaria Regional de Educação $\Xi$ Universidade de Madeira, Madeira, Portugal
}

\begin{abstract}
Resumo
As transformações das sociedades nos últimos anos remetem para a necessidade de ajustamentos e novas dinâmicas de acção nos sistemas educativos e nas relações entre os seus agentes. À educação e formação de cidadãos têm-se vindo a associar novos profissionais, designadamente os psicólogos, de quem se espera um contributo para a eficácia dos sistemas educativos no cumprimento da sua missão. Defende-se, porém, que essa intervenção seja desenvolvida de um modo específico e marcada pela integração na comunidade educativa, pela colaboração e pela prevenção. Aborda-se, assim, a intervenção do psicólogo na escola, identificando algumas dinâmicas da sua intervenção e sugerindo alguns aspectos que a devem caracterizar.

Palavras-chave: Psicologia Escolar; serviços de psicologia e orientação; abordagem ecológica.
\end{abstract}

\begin{abstract}
The profound transformations of societies in the recent years address the necessity of adjustments and new dynamics in the educative systems and in the relationship among its agents. It is in this context that new professionals such as psychologists have been involved in the education and training process of citizens. It is expected from them to contribute to the educational system efficacy in it's mission delivery. It is expected, however, that this intervention is developed in a specific way and marked by the principles of prevention, collaboration and educative community integration. The intervention of psychologist is therefore approached in the text, in which the author identifies some dynamics of that intervention and suggests some aspects that should characterize it

Keywords: School Psychology; counselling and psychology services; ecological approach.
\end{abstract}

\section{Os Novos Desafios aos Sistemas Educativos}

Não podendo consistir em instituições estagnadas ou pouco dinâmicas, necessitando de uma actualização de acordo com as mudanças no mundo, os sistemas educativos não deixaram de acompanhar as evoluções ocorridas nos últimos anos e as novas realidades sociais, políticas e económicas. No caso da escolaridade obrigatória, independentemente da extensão das reformas curriculares e estruturais dos sistemas educativos, todos os países efetuaram mudanças nos últimos anos (Eurydice, 1997). Por exemplo, ao nível dos conteúdos, já não se trata somente de saber ler, escrever e da aritmética, incluindo-se agora um variado leque de competências, designadamente o conhecimento das novas formas de comunicação e de acesso à informação, as línguas estrangeiras ou ainda as disciplinas associadas às tecnologias de informação.

Tendo em conta esta nova complexidade, introduziramse novos temas transdisciplinares, relacionados com a análise de problemas actuais, a que se associam os domínios de conhecimento relacionado com comportamento cívico

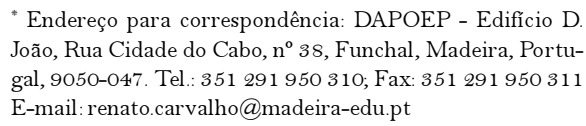

Endereço para correspondência: DAPOEP - Edifício D João, Rua Cidade do Cabo, $n^{\circ} 38$, Funchal, Madeira, Portugal, 9050-047. Tel.: 351291950310 ; Fax: 351291950311 E-mail: renato.carvalho@madeira-edu.pt

e social, competências para a sociedade do conhecimento e aprendizagem ao longo da vida. É ainda de realçar a promoção da aquisição de estratégias de pensamento e ferramentas intelectuais para facilitar novas formas de aprendizagem no futuro, sendo mais valorizadas a aquisição de atitudes e de competências de mestria do que a mera acumulação de factos e figuras.

Com efeito, a multiculturalidade da sociedade, os padrões de desenvolvimento ambiental sustentável, a igualdade de género, a cidadania europeia, a educação sexual, o desenvolvimento vocacional, são elementos que caracterizam o mundo actual e colocam novos desafios aos sistemas educativos.

Como Valore (2003) menciona, não há como ignorar o facto dos avanços tecnológicos, o processo de globalização e de criação de uma nova economia, a imprevisibilidade dos novos tempos e o reconhecimento do paradigma da incerteza na construção do conhecimento estarem a exigir novas competências técnicas e pessoais, sofisticando o ideário da qualificação profissional e, consequentemente, incrementando as exigências direccionadas à formação escolar, a fim de aproximá-la às demandas do mundo do trabalho.

Paiva Campos (2004) refere que não podemos negar as diversas mudanças sociais que vivemos, como sejam a 
maior heterogeneidade da população escolar, a multiplicação das fontes de informação ou a maior autonomia oferecida às escolas. Estas mudanças fazem emergir a necessidade de recorrer a novos processos ou de reestruturar os tradicionais, de organização do contexto e das oportunidades de aprendizagem.

Torna-se cada vez mais necessário o trabalho interdisciplinar e de projecto, não bastando a justaposição de disciplinas e conteúdos disciplinares. É, assim, reconhecida a complexidade da Educação e das tarefas que a esta estão associadas, pelo que cada vez é mais proeminente o estabelecimento de novas práticas e paradigmas de intervenção em contexto educativo, bem como a interacção entre diversos profissionais, em que se inserem os psicólogos.

De facto, as características do mundo pós-moderno e as novas competências a que apela, exigem uma melhor capacidade de resposta dos sistemas educativos e das nossas escolas, no sentido da formação de cidadãos aptos para lidar com os novos desafios. Ora, é justamente nessa perspectiva que é realçado o contributo que as diferentes áreas do saber podem apresentar na configuração de respostas mais eficazes.

\section{O Papel da Psicologia e da Orientação}

A psicologia apresentou efectivamente uma evolução significativa nos últimos anos, tendo, em relação ao domínio escolar e educativo, sido publicados diversos trabalhos científicos relativos à utilidade e amplitude do seu contributo. De tal modo que, apesar da presença dos profissionais desta área não ser ainda suficientemente alargada em termos nacionais, é-lhes reconhecido um importante papel, não só na perspectiva do trabalho para a resolução de problemáticas relacionadas com os alunos, mas também na preparação dos jovens para o seu futuro, no acompanhamento do fenómeno educativo e na participação em processos de decisão.

$\mathrm{Na}$ realidade, podem ser identificados diversos domínios de intervenção, sendo importante destacar a importância que, por exemplo, a promoção de competências de desenvolvimento e maturidade vocacional, numa lógica de perspectiva temporal de futuro, têm no contexto da sociedade actual.

A este propósito é importante referir que é o próprio Conselho da União Europeia (CUE) ${ }^{1}$ que reconhece, embora uma perspectiva mais transdisciplinar, a importância da orientação, principalmente ao longo da vida, tendo em conta a realidade actual. O CUE mostra-se ciente (pp. 23), por exemplo, que:

1. No contexto de aprendizagem ao longo da vida, a orientação inclui um conjunto de actividades que permitem aos cidadãos de todas as idades e em qualquer momento da vida identificar as suas capacidades, com-

${ }^{1}$ Projecto de Resolução do Conselho e dos Representantes dos Estados-Membros reunidos no Conselho relativo ao reforço das políticas, sistemas e práticas no domínio da orientação ao longo da vida na Europa (9286/04, de 18 de Maio de 2004). petências e interesses, tomar decisões em matéria de educação, formação e ocupação, e gerir o seu percurso individual no ensino, trabalho e outras situações em que estas capacidades e competências são adquiridas e/ou utilizadas.

2. À orientação no âmbito do sistema educativo e de formação, particularmente nas escolas ou a nível escolar, cabe um papel importante para garantir que as decisões de cada um em matéria de educação e profissão sejam tomadas numa base sólida e para contribuir para que cada indivíduo desenvolva uma gestão autónoma do respectivo percurso no ensino e na carreira profissional. Constitui também um instrumento fundamental para os estabelecimentos de ensino e formação, a fim de aumentarem a qualidade da sua oferta . . .

3. A orientação eficaz tem um papel fundamental a desempenhar na promoção da inclusão social, da equidade social, da igualdade entre os sexos e da cidadania activa, através do incentivo e do apoio aos indivíduos para que participem na educação e na formação e façam as suas opções no sentido de uma carreira realista e em que se realizem.

O Conselho da Europa salienta ainda "o papel preventivo dos serviços de orientação no sentido de evitar o abandono escolar e o contributo por eles prestado para habilitar os cidadãos a gerirem a sua aprendizagem e as suas carreiras, bem como para a reintegração daqueles que abandonaram prematuramente a escola em programas adequados de educação e formação", bem como "a centralidade dos benefícios da orientação, na concepção como na avaliação da prestação de orientação tanto a jovens como a adultos" (p. 7).

Ao nível da escolaridade obrigatória, por outro lado, a Organização para a Cooperação e Desenvolvimento Económico ([OCDE], 2005), identifica uma série de problemas e desafios cuja maioria, se se atentar, enquadra-se no âmbito da missão e das competências dos serviços de psicologia também nas escolas. Um exemplo é importância da intervenção precoce, na senda do desenvolvimento das bases para a aquisição de competências de auto-gestão da carreira (tomada de decisão, conhecimento de si próprio, auto-confiança). A OCDE pronuncia-se também sobre a questão das transições escolares, por exemplo do $1^{\circ}$ para o $2^{\circ}$ ciclo do Ensino Básico, afirmando que os jovens necessitam de a preparar, devendo ser a orientação parte integrante desse processo.

É ainda de mencionar a referência ao facto dos processos de orientação, no $2^{\circ}$ e $3^{\circ}$ ciclos do Ensino Básico se destinarem a jovens que se encontram em pontos importantes de tomada de decisão no sistema educativo (escolha de disciplinas; antes do final da escolaridade obrigatória; transição para o Ensino Secundário ou mundo do trabalho). A sua pertinência é sobretudo sustentada pelo facto dos jovens apresentarem, por exemplo, uma baixa maturidade vocacional ou dificuldades de tomada de decisão.

Em suma, é neste quadro de maior exigência aos sistemas educativos e à Educação, no sentido da melhor preparação dos jovens, que surge um importante contributo do 
psicólogo. E, apesar da sua chegada às escolas se tratar de um fenómeno relativamente recente, o seu papel e participação são sucessivamente consolidados e reconhecidos, havendo uma acessibilidade de atitudes cada vez mais significativa em relação a si.

Com efeito, cada vez mais o psicólogo é parte integrante do sistema escolar e a sua intervenção solicitada. Movimentando-se e interagindo com os restantes agentes educativos, preferencialmente de modo colaborativo, o psicólogo é hoje um elemento central na Escola e que, mobilizando os seus saberes e as suas competências, contribui para um objectivo central da Educação: o sucesso escolar, a formação de cidadãos.

\section{Uma Abordagem Ecológica, Colaborativa e Preventiva}

A intervenção do psicólogo na Escola é também marcada pela história da psicologia em geral e da psicologia educacional em particular. Esta, ao longo da história, viu-se confrontada com uma sucessiva acumulação de funções, associadas ao evoluir das necessidades e oportunidades sociais e ao evoluir dos próprios modelos teóricos de referências.

Esta situação evidencia a necessidade do psicólogo educacional, ao planificar a sua acção e intervenção, ter de proceder a escolhas. Carita (1996), por exemplo, evoca a passagem do modelo psicométrico ao clínico e deste, passando pelo investigativo, aos modelos ecológicos e comunitários.

A necessidade de empreender acções com outros agentes, designadamente professores, ao serviço de um "cliente" comum, o aluno, sugere a opção por determinadas estratégias de abordagem em detrimento de outras (Coimbra, 1991). Ora, a teoria ecológica, que conceptualiza o comportamento humano como função de interacções entre as características do indivíduo e os múltiplos ambientes em que funciona, apresenta grande potencial como uma orientação eficaz no âmbito da psicologia na escola (Sheridan \& Gutkin, 2000). Isto é, o modelo ecológico privilegia a compreensão do ser humano de maneira ampla e sistémica (De Antoni \& Koller, 2001).

Apter e Conoley (1984) sugerem 4 asserções da teoria ecológica, designadamente:

1. o facto de cada criança ser uma parte inseparável de um pequeno sistema social.

2. as perturbações não serem apenas vistas como localizadas na criança, mas sobretudo ao nível do sistema, o que requer também uma avaliação de factores ambientais.

3. a discordância poder ser definida como uma disparidade entre as capacidades do indivíduo e as expectativas ou exigências do ambiente - falha na compatibilização entre criança e ambiente.

4. o objectivo de qualquer intervenção é fazer o sistema funcionar.

De facto, nem os psicólogos, nem os professores, nem os alunos, funcionam em isolamento. Somos influenciados pelos múltiplos sistemas que nos rodeiam e dos quais fazemos parte (Bronfenbrenner, 1977, 1979, 1993) e, assim, não poderemos efectuar intervenções eficazes descontextualizando os problemas das crianças e dos jovens como patologias internas, como o modelo médico nos diria.

É, portanto, necessário, entender o modo como a "disfunção” está relacionada com sistemas mais abrangentes e encontrar meios para intervir eficazmente com estes sistemas (Sheridan \& Gutkin, 2000).

As "disfunções" são melhor entendidas como o produto de sistemas multilaterais, proximais, distais e interactivos. Entre estes sistemas encontram-se as crianças, os contextos educacionais, os ambientes sociais prevalecentes, sistemas familiares, variáveis das comunidades locais, influências da sociedade e a interacção entre todos estes sistemas (Sheridan \& Gutkin, 2000). Como referenciado pelo modelo (PPCT), de Bronfenbrenner (1993), há que ter em conta quatro elementos do sistema ecológico, que se apresentam em permanente interacção dinâmica: a pessoa, o processo, o contexto e o tempo. Só assim se poderá efectivar uma abordagem verdadeiramente adaptada às necessidades de cada indivíduo e adoptar procedimentos conducentes ao sucesso.

Todas estas asserções são fundamentais na intervenção do psicólogo na escola, na medida em que a rejeição de um modelo médico de intervenção e a contemplação de uma perspectiva sistémica e ecológica remete para toda uma série de procedimentos de interacção e colaboração, para os quais os diversos agentes educativos podem ainda não estar inteiramente preparados.

Como refere Coimbra (1991), o impacto da intervenção do psicólogo depende, em larga medida, da forma como se situa em relação aos outros profissionais existentes na escola e da maneira como é percepcionado por estes. Ora, é justamente nesta perspectiva que, como Carita (1996) menciona, deve existir uma ênfase no reconhecimento da importância da integração do psicólogo no quotidiano da escola, na sua vida e no seu desenvolvimento enquanto organização.

Incentivar a criação de espaços de participação e cooperação inter-profissionais, ou estar activamente presente nos já instituídos, colaborar muito especialmente com os elementos mais activos, abertos e empenhados, parece ser uma orientação a privilegiar (Carita, 1996). Sem perder de vista o aluno, enquanto principal destinatário da intervenção, é muito no sentido de um trabalho de parceria com professores, pais e outros agentes, que aquela se pode organizar.

Por outro lado, é também num contexto de um trabalho conjunto que melhor podemos exercer a nossa influência, quer através das ideias e propostas que passamos e discutimos, quer através daquilo que nos disponibilizamos a fazer.

O modelo ecológico apresenta uma grande vantagem sobre o modelo médico tradicional, que é justamente o facto de localizar o problema na interacção entre o indivíduo e o sistema, nas discrepâncias entre as competências de uma criança e as expectativas do seu ambiente. A inter- 
venção é assim mais dirigida à esfera total da vida da criança e ao seu desenvolvimento (Apter \& Conoley, 1984).

Coimbra (1991), de resto, distingue duas grandes tipologias em termos da intervenção do psicólogo na escola: o modelo do especialista e o modelo colaborativo (Pinc, 1981; Tyler, 1983, apud Coimbra, 1991). O primeiro acentua a dimensão técnica e tecnológica, em que o saber do psicólogo é validado pela analogia de práticas profissionais de peritagem noutros domínios como a medicina ou as tecnologias. O modelo colaborativo enfatiza, por outro lado, a responsabilidade e participação e releva o psicólogo como um profissional da educação, cuja intervenção ocorre a par da de outros profissionais da educação. Estas diferentes perspectivas acarretam, naturalmente, algumas consequências, sendo de destacar a actuação estanque entre psicólogos e professores, que dificulta a colaboração e se associa ao modelo especialista; e, no caso do modelo colaborativo, a abordagem global e interdisciplinar, conducente a decisões negociadas e partilhadas.

\section{Os Serviços de Psicologia no Ambito \\ de um Paradigma Ecológico}

Coll (1989) define quatro eixos englobantes do conjunto de funções atribuídas à psicologia escolar: (a) a natureza dos objectos, que oscilariam entre um pólo pedagógico e um psicológico; (b) as modalidades de intervenção: intervenção enriquecedora (primária), preventiva (secundária), remediativa (terciária); (c) a intervenção directa ou imediata sobre o aluno e uma intervenção indirecta, mediatizada; (d) o lugar preferencial de intervenção: sala de aula, instituição escolar, comunidade.

De forma a realizar o seu potencial profissional, os serviços de psicologia devem estar ligados aos sistemas ambientais que rodeiam as crianças com quem lida (Sheridan \& Gutkin, 2000). Especificamente, os psicólogos devem desenvolver ligações fortes com as escolas, famílias e comunidades, numa lógica de proximidade com professores, assistentes sociais, técnicos de educação especial, pessoal de apoio e pais.

Até porque o bem-estar das crianças está altamente relacionado com a estabilidade e bem-estar, por exemplo, das famílias das quais fazem parte (American Psychological Association, 1994). De resto, os benefícios do envolvimento parental na educação dos seus filhos são inequívocos, devendo, por isso, ser explorados processos através dos quais famílias e escolas podem agir em parceria.

Nesta perspectiva, os psicólogos escolares deverão preocupar-se sobretudo com a prevenção e promoção do bemestar das crianças, mais do que com a identificação do que está errado, medindo problemas e fornecendo soluções de remediação - isto é, envolvendo-se e conduzindo pesquisa nos serviços que permitam ao estudante ser bem sucedido na vida (Meyers \& Nastasi, 1999). As intervenções primária e secundária são essenciais, por exemplo, para prevenir a violência, abuso de substâncias, abandono escolar, gravidez adolescente, entre outros.

$\mathrm{Na}$ abordagem destas problemáticas e do modo com se perspectivam as "disfunções", é ainda importante subli- nhar alguns factores, mencionados, por exemplo, por Bronfenbrenner e Morris (1998), designadamente as disposições, os recursos e as demandas da pessoa, elementos que contribuem para uma melhor definição da mesma.

Uma interacção particularmente relevante em contexto escolar é a que se estabelece entre o psicólogo e os docentes. Nesta perspectiva, Sheridan e Gutkin (2000), salientam alguns aspectos que devem ser contemplados nessa interacção:

(a) Os professores devem ter as competências necessárias para implementar intervenções correctamente ou estar dispostos a aprendê-las; (b) Os professores devem perceber que têm a capacidade necessária para implementar os planos de intervenção; (c) Os professores não deverão implementar um plano de intervenção na sua sala de aula com o qual não concordem; (d) As intervenções propostas devem ser vistas pelos professores como um aspecto legítimo do seu papel. Muitos psicólogos escolares lidaram com professores que recusaram implementar intervenções porque as entenderam como indo além das suas responsabilidades; (e) As intervenções devem encaixar na ecologia natural em que irão ser implementadas, sem causar, por isso, grandes cortes ou disjunções.

Este tipo de abordagem, adaptado à ecologia e à realidade sistémica desta escola em particular, justifica-se pelo facto das organizações escolares, ainda que estejam integradas num contexto cultural mais amplo, produzirem uma cultura interna que lhes é própria e que exprime os valores e as crenças que os membros da organização partilham (Nóvoa, 1995, apud Carvalho, 2006b).

Ora, é justamente neste sentido que também não se poderá esquecer que deve também ser considerada uma realidade local e particular diversa, que frequentemente intervém activamente sobre as orientações e directrizes provenientes do nível macro (Carvalho, 2006b). Assim, a intervenção dos serviços de psicologia, que se inserem nesta realidade, deverá também ter em conta estas circunstâncias, procurando uma compreensão desta cultura específica de cada escola, o que irá potenciar a sua acção.

Por outro lado, não se pode deixar de privilegiar uma abordagem contextualizada e ecológica também às práticas de orientação. Uma vez que a orientação escolar e profissional é um domínio que envolve a ajuda no estabelecimento e na implementação de projectos de vida, a mesma pode ser considerada uma área que integra as diferentes dimensões da existência humana (educacional, familiar, profissional, etc.) (Centro Nacional de Recursos para a Orientação Vocacional, 2002).

De facto, a actividade humana é vista como uma acção no contexto que, como tal, não depende exclusivamente de dimensões psicológicas íntimas. Torna-se, por conseguinte, essencial compreender o papel dos contextos de vida no processo de desenvolvimento pessoal (Centro Nacional de Recursos para a Orientação Vocacional, 2002).

Com a OEP, pretende-se alcançar diversos objectivos, designadamente ajudar os alunos a reflectir sobre as suas experiências, interesses, capacidades e expectativas, apoian- 
do-os na construção da sua identidade pessoal e projecto de vida, bem como promover e desenvolver nos jovens o seu auto-conceito. Em específico, pretende-se desenvolver programas e acções de aconselhamento pessoal e vocacional, individualmente ou em grupo, informando e proporcionando a exploração dos alunos sobre as oportunidades escolares e profissionais, mas também fomentando a atitude de iniciativa, espírito crítico e hábitos de trabalho e pesquisa nos jovens.

A intervenção deve decorrer de forma dialéctica, destacando a participação e contributo do indivíduo. Até porque este processo de intervenção desenrola-se de acordo com as necessidades e progressão dos indivíduos, o que implica que o profissional não se centre no planeamento rígido e pré-estabelecido de actividades.

Como Coimbra, Campos e Imaginário (1994) referem, a capacidade para gerir o processo de intervenção é a principal competência que se pede aos profissionais de orientação. Tal não significa que não devam planear a sua intervenção. Pelo contrário, o que se propõe é que elaborem um projecto baseado na definição de determinados princípios de estruturação, a partir da qual a intervenção se irá progressivamente desenvolvendo e tomando forma (Centro Nacional de Recursos para a Orientação Vocacional, 2002).

\section{A Importância do Tipo de Abordagem}

Na Escola, o psicólogo pode intervir em diversos domínios, como sejam o apoio psicológico e psicopedagógico, a orientação vocacional ou o apoio ao sistema de relações da comunidade educativa. De resto, são esses três domínios de actividade que a legislação portuguesa identifica, por exemplo, através do Decreto-Lei n 190/91, de 17 de Maio, que cria os Serviços de Psicologia e Orientação. Desde então, a sua actividade tem sido incrementada, estando hoje mais acessível do ponto de vista atitudinal dos diversos agentes.

Mas, se, por um lado, é certo que a presença do psicólogo em contexto escolar é cada vez mais frequente, existindo, consequentemente, um sucessivo incremento da acessibilidade das atitudes face a este profissional por parte de outros agentes (pais, professores, administradores educacionais, etc.), por outro lado, também não deixa de ser certo que há ainda um caminho a percorrer no sentido do entendimento do que é a intervenção do psicólogo na escola (Carvalho, 2006a).

Na realidade, pode constatar-se que, com frequência, não existem ainda concepções claras do que faz um psicólogo na escola, o que naturalmente também se associa ao facto destes profissionais terem apenas surgido no contexto educativo há relativamente pouco tempo na História. Esta situação faz com que, apesar da intervenção do psicólogo estar já contemplada há algum tempo em termos legais, nas escolas possam não estar ainda muito bem claras essas atribuições.

Nesta perspectiva, um dos aspectos que assume grande relevância, em especial na chegada de um psicólogo à es- cola, é justamente a sensibilização e informação dos diversos agentes em relação às suas atribuições. A resposta à questão “o que faz um psicólogo na escola?" é, por isso, muito importante, sendo transmitida informação sobre as suas atribuições, o seu papel e as actividades que pode desenvolver. De resto, não se trata apenas de uma abordagem inicial, mas contínua, já que esta preocupação "pedagógica", de esclarecer os diversos agentes sobre as funções do psicólogo, deve estar sempre presente na acção quotidiana.

Assim, aquando das diversas intervenções, deve existir a preocupação de se efectuarem tais esclarecimentos, designadamente junto dos órgãos de gestão, dos professores, pais, alunos e demais funcionários não docentes da escola. Esta postura inicia-se, desde logo, em sessões de abertura do ano lectivo e reuniões iniciais preparatórias, em que estejam presentes os membros do órgão de gestão, professores e o psicólogo. De resto, esta abordagem é necessária também pelo facto de existir frequentemente ideias erróneas sobre as funções dos psicólogos na escola (e.g., considerar-se que, por trabalhar em contexto escolar, o psicólogo é da área educacional).

Um outro elemento fulcral na intervenção e preocupação permanente é o conhecimento da realidade sistémica da escola, isto é, do meio e da comunidade educativa. Só se pode intervir com eficácia, conhecendo a realidade contextual e, neste sentido, deve-se desde logo conhecer a escola, os seus espaços, os professores, os funcionários, a direcção, a forma como a escola surgiu, especialmente nas que foram edificadas mais recentemente. Em suma, saber quais as especificidades da realidade da escola, conhecimento que favorece não só a integração, mas também as intervenções implementadas.

A este aspecto associa-se um outro, também fulcral e condição inequivocamente necessária para o sucesso: a integração na comunidade educativa. De facto, não se poderá contemplar uma perspectiva ecológica sem uma lógica relacional em que o psicólogo esteja integrado. Ora, é justamente nesta perspectiva que, desde logo, a postura deve ser de abertura, de interacção e contacto frequente com os diversos agentes educativos, considerados parceiros.

Tal circunstância traduz-se não só em contactos em momentos formais de interacção (reuniões, briefings, etc.), mas também em momentos informais e na participação em actividades da escola. Rejeita-se, por isso, a lógica do técnico que se encontra isolado no seu gabinete, privilegiando-se o contacto frequente, o diálogo e a própria socialização.

Esta postura promove, não só um bom ambiente de trabalho e relacional, do ponto de vista pessoal, mas também uma maior dinâmica na mobilização de recursos, estratégias e agentes no sentido da resolução dos problemas, na organização de actividades e na inter-ajuda e cooperação. Portanto, o bom e frequente relacionamento entre os diversos agentes é um contributo incontornável para uma maior eficácia e eficiência das intervenções.

Por fim, e tendo em conta a não preparação das escolas, em termos de espaços físicos e logística, para a actividade 
de vários técnicos, como sejam os psicólogos, deve tentarse assegurar condições aceitáveis de trabalho, de forma a ser desenvolvida uma acção que respeite a própria ética profissional, por exemplo, através da salvaguarda de condições de confidencialidade, em espaços de trabalho próprios.

Em suma, é de valorizar uma intervenção orientada por quatro eixos centrais, caracterizados pela:

1. Integração na comunidade educativa, como requisito para (a) o desenvolvimento de um bom trabalho; (b) para a promoção de uma maior acessibilidade de atitudes dos diversos agentes em relação ao papel do psicólogo; (c) e como forma de potenciar as vantagens da intervenção do psicólogo em contexto escolar, maximizando a sua eficácia.

2. Cooperação entre diversos agentes, na tentativa de resolução dos problemas e no modo como se encararam e estruturaram as diversas actividades, rejeitando-se o isolamento do técnico no seu gabinete.

3. Participação nos órgãos e processos de decisão e, em geral, nas diversas actividades desenvolvidas na escola, não apenas as desenvolvidas pelo SPO.

4. Prevenção, apostando em estratégias que pretendem diminuir a possibilidade de surgimento de problemáticas futuras, evitando-se, com isso, estratégias de remediação.

\section{Referências}

American Psychological Association. (1994). Comprehensive and coordinated psychological services for children: A call for service integration. Washington, DC: Author.

Apter, S. J., \& Conoley, J.C. (1984). Childhood behavior disorders and emotional disturbance: An introduction to teaching troubled children. Engkewood Cliffs, NJ: Prenctice-Hall.

Bronfenbrenner, U. (1977). Toward an experimental ecology of human development. American Psychologist, 32, 513-531.

Bronfenbrenner, U. (1979). The ecology of human development. Cambridge, MA: Harvard University Press.

Bronfenbrenner, U. (1993). The ecology of cognitive development: Research models and fugitive findings. In R. Wozniak $\&$ K. Fischer (Eds.), Development in context: Acting and thinking. in specific environments (pp. 3-44). Hillsdale, NJ: Erlbaum.

Bronfenbrenner, U., \& Morris, P. (1998). The ecology of developmental processes. In W. Damon (Ed.), Handbook of Child Psychology (Vol. 1, pp. 993-1027). New York: Wiley \& Sons.

Carita, A. (1996). O psicólogo na escola: Factores condicionantes e sentido geral da intervenção. Análise Psicológica, 1(14), 123128.

Carvalho, R. G. (2006a, fev.). Áreas de intervenção do psicólogo na escola: Estudos e projectos de investigação. Comunicação apresentada na I Conferência Psicologia do Educar, Funchal, Portugal.

Carvalho, R. G. (2006b, jun.). Cultura global e contextos locais: A escola como instituição possuidora de cultura própria. Revista Iberoamericana de Educação, 29(2). Retirado em dez. 2006, de http://www.rieoei.org/1434.htm

Centro Nacional de Recursos para a Orientação Vocacional (2002). Rosa dos Ventos - Guia do Profissional de Orientação. Lisboa, Portugal: Ministério da Educação.
Coimbra, J. L. (1991). O psicólogo face aos outros profissionais da Educação: Reflexões sobre a consultadoria psicológica. Cadernos de Consulta Psicológica, 7, 21-26.

Coimbra, J. L., Campos, B. P., \& Imaginário, L. (1994). Career intervention from a psychological perspective: Definition of the main ingredients of an Ecological-developmental methodology. Comunicação apresentada no $23^{\circ}$ Congresso Internacional de Psicologia Aplicada, Simpósio sobre Desenvolvimentos e Contributos Recentes de/para as Práticas de Intervenção Psicológica nas Carreiras, Madrid, Espanha.

Coll, C. (1989). Conocimiento psicológico y práctica educativa. Barcelona, España: Barcanova.

De Antoni, C., \& Koller, S. H. (2001). O psicólogo ecológico no contexto institucional: Uma experiência com meninas vítimas de violência. Psicologia: Ciência e Profissão, 21(1), 19-29.

Eurydice (1997). A decade of reforms at compulsory education level (1984-1994). Retirado em fev. 2006, de http://www.eurydice. org/Documents/ref20/en/FrameSet.htm

Meyers, J., \& Nastasi, B. K. (1999). School psychologists as health-care providers in the 21 st century. In C. R. Reynolds $\&$ T. B. Gutkin (Eds.), The handbook of School Psychology (3nd edition, pp. 764-799). New York: Wiley.

Organização para a Cooperação e Desenvolvimento Económico. (2005). Orientação escolar e profissional - Guia para decisores. Lisboa, Portugal: Direcção Geral de Inovação e Desenvolvimento Curricular e Instituto de Orientação Profissional.

Paiva Campos, B. (2004), Novas dimensões do desempenho e formação de professores. Discursos: Série Perspectivas em Educação, 2, 13-26.

Sheridan, S., \& Gutkin, T. (2000). The ecology of School Psychology: Examining and changing our paradigm for the 21 st Century. School Psychology Review, 29(4), 485-502.

Valore, L. (2003, jul.). O que você vai ver quando crescer? O psicólogo, a escola e a orientação profissional: Articulações possíveis. Revista Electrónica de Psicologia, 2. Retirado em mar. 2006, de http://www.utp.br/psico.utp.online.
Recebido: 1s/12/2006 $1^{a}$ revisão: 13/0s/2007 $2^{a}$ revisão: 02/05/2007 Aceite final: 08/08/2007 